\title{
Professional Ethical Consideration in Esthetic Dental Practice: A Survey among Dentists in Riyadh, Kingdom of Saudi Arabia
}

\author{
Sara A Alshammery
}

\begin{abstract}
Objective: The purpose of the study was to assess the professional ethical consideration in esthetic dental practice of the dentists practicing in Ar-Riyadh region, Kingdom of Saudi Arabia.

Materials and methods: A modified version of the questionnaire on dental ethics in esthetic dentistry (Bernstein, 2008), written in both English and Arabic was prepared. The questionnaire, designed to obtain information from dentists regarding their beliefs in ethics in esthetic dentistry was administered to dentists practicing in the Ar-Riyadh region of the Kingdom of Saudi Arabia. The study comprised of 305 participants who returned the completed questionnaire.

Results: In total, 400 questionnaires were distributed with an overall response rate of $76.25 \%$. The respondents comprised of 256 Saudi and 49 non-Saudi dentists.

The role of the dentists in persuading and encouraging patients to have cosmetic treatment and the role that a patient's finances played in influencing esthetic dental treatment, tooth reduction was not found to be significant for different clinical titles, gender and years of experience except Saudi dentists who reported significantly higher emphasis on the role of the dentist in persuading and encouraging the patient to undergo cosmetic treatment. A significant majority of the dentists stated that they would reduce less than $2 \mathrm{~mm}$ of tooth structure and they had a full obligation to TMJ and occlusion while performing an esthetic procedure and also they reported journals as a source of their information Conclusion: Within the limitation of the study it can be concluded that ethics comprises of basic values and practice issues, Basic values do not change however, practice issues may be influenced by experience and clinical title and It is interesting that gender does not seem to influence the ethics of practicing esthetic dentistry, so as ending ethics is knowing the difference between what you have a right to do, and what is right to do. Keywords: Ethics, Esthetic dentistry, Saudi dentists.
\end{abstract}

Journal of Oral Health and Community Dentistry (2019): 10.5005/jp-journals-10062-0039

\section{INTRODUCTION}

Esthetic dentistry has assumed a central role in dental practice the E world over. ${ }^{1}$ While esthetics deals with beauty (both subjective and objective), ethics govern the morality behind that beauty. ${ }^{2-4}$

Dentists assume unique moral duties in presenting themselves to society as being uniquely qualified to care for their oral health. ${ }^{5}$ Despite the moral necessity of ethics, the issue of whether those ethics are compatible with dental practice is one that has been raised repeatedly in the literature. ${ }^{6-10}$

Esthetic or cosmetic dentistry is often viewed, by patients and dentists alike, as a lucrative field that provides elective dental care. ${ }^{9}$ While some authors have pointed out that esthetic dentistry is more than merely satisfying patient demands ${ }^{11-13}$ the lack of focus on the issue of ethics in esthetic dentistry has also been lamented. ${ }^{11}$

While the dental literature is filled with articles that assess the practice of esthetic dentistry, considerably fewer papers have focused on the ethics that underlie that practice. Papers on the practice of esthetic dentistry have placed the onus of ethical practice on the dentist noting that the decision-making ability of the dentist would help to judge and plan the best treatment services to meet the patient needs. ${ }^{1,11,12,14-17}$

Dentistry in the Kingdom of Saudi Arabia has made rapid advances in the past few decades, and today the Kingdom has over 8700 dentists. The community of dentists is a blend of Saudi (15\%) and non-Saudi dentists, drawn from 74 countries. There have been reports in the medical literature that race, cultural and religious beliefs may influence certain decisions of doctors. ${ }^{18}$

Given the multinational background of the dental workforce it is important to assess differences, if any, in the application of ethical codes.

\section{Lecturer}

Department of Restorative, Riyadh ELM University, Riyadh, Kingdom of Saudi Arabia

Corresponding Author: Sara A Alshammery, Lecturer, Department of Restorative, Riyadh ELM University, Riyadh, Kingdom of Saudi Arabia, e-mail: sara@riyadh.edu.sa

How to cite this article: Alshammery SA. Professional Ethical Consideration in Esthetic Dental Practice: A Survey among Dentists in Riyadh, Kingdom of Saudi Arabia. J Oral Health Comm Dent 2019;13(1):10-13.

Source of support: Nil

Conflict of interest: None

Keeping in mind the lack of data on the subject of ethical issues in esthetic dentistry in the Kingdom of Saudi Arabia, and the unique cultural, ethnic and demographic nature of dental practice in the Kingdom, it was decided to conduct a study on the dentists practicing in Ar-Riyadh region to assess their professional ethical consideration in esthetic dental practice. ${ }^{19-21}$

\section{Materials and methods}

\section{Preparation of the Instrument}

A modified version of the questionnaire on dental ethics in esthetic dentistry (Bernstein, 2008), written in both English and Arabic was prepared. The seven most important factors influencing the practice of esthetic dentistry in Saudi Arabia were elicited after interviews with senior consultants in the field of esthetic dentistry. The questionnaire was then administered to a sample of 20 individuals to assess reliability (Cronbach's alpha 0.76) and validity. Oncethe validity of the instrument was established the instrument was distributed among the study population.

(0) The Author(s). 2019 Open Access This article is distributed under the terms of the Creative Commons Attribution 4.0 International License (http://creativecommons. org/licenses/by/4.0/), which permits unrestricted use, distribution, and non-commercial reproduction in any medium, provided you give appropriate credit to the original author(s) and the source, provide a link to the Creative Commons license, and indicate if changes were made. The Creative Commons Public Domain Dedication waiver (http://creativecommons.org/publicdomain/zero/1.0/) applies to the data made available in this article, unless otherwise stated. 


\section{Sample Size Calculation}

Sample size estimation was done by using $\mathrm{G}$ Power software (version 3.0). The sample size was estimated for one way analysis of variance (ANOVA) test A minimum total sample size of 400 was found to be sufficient for an alpha of 0.05 , power of $95 \%, 0.25$ as effect size (assessed from a similar study).

\section{Sampling and Distribution of the Questionnaire}

Four hundred dentists practicing in the Ar-Riyadh region of Saudi Arabia were selected using stratified convenience sampling. The dentists were stratified according to their clinical title as general practitioners (GPs) $(n=100)$, specialists $(n=100)$, senior specialists ( $n=100)$ and consultants ( 100$)$. The questionnaire was sent out with a covering letter, 305 participants returned the completed questionnaire and were included in the study.

\section{Statistical Analyses}

The returned questionnaire papers were reviewed and analyzed according to the choices of the dentists in general and for each question. As data failed to follow a normal distribution; nonparametric tests of significance was used. Pearson's Chi-square test was used to measure the significance of the difference between responses. The Kruskal-Wallis test was used to measure the significance of the difference between different groups in each question. Questions with multiple responses were grouped into sets and the Freidman test was used to determine significance between the groups within a set. All data were processed using the statistical package for social sciences (SPSS) version 19 data processing software.

\section{Results}

Of the 400 questionnaires distributed we received 305 (206 males, 99 females) questionnaires with an overall response rate of $76.25 \%$ (Graph 1). The respondents comprised of 256 Saudi and 49 nonSaudi dentists.

When asked about the role of the dentists in persuading and encouraging patients to have cosmetic treatment a significant majority of the dentists felt that the dentists' role was approximately $70 \%$ (Chi-square 51.78, $p<0.001)$. When the answer was compared among the different clinical titles using the Kurskul Wallis test, we found no significant difference between the different clinical titles (Chi-square 1.054, $p<0.658$ ), gender (Chi-square 3.166, $p<0.075$ ) or years of experience (Chi-square $1.61, p<0.447)$. However, when

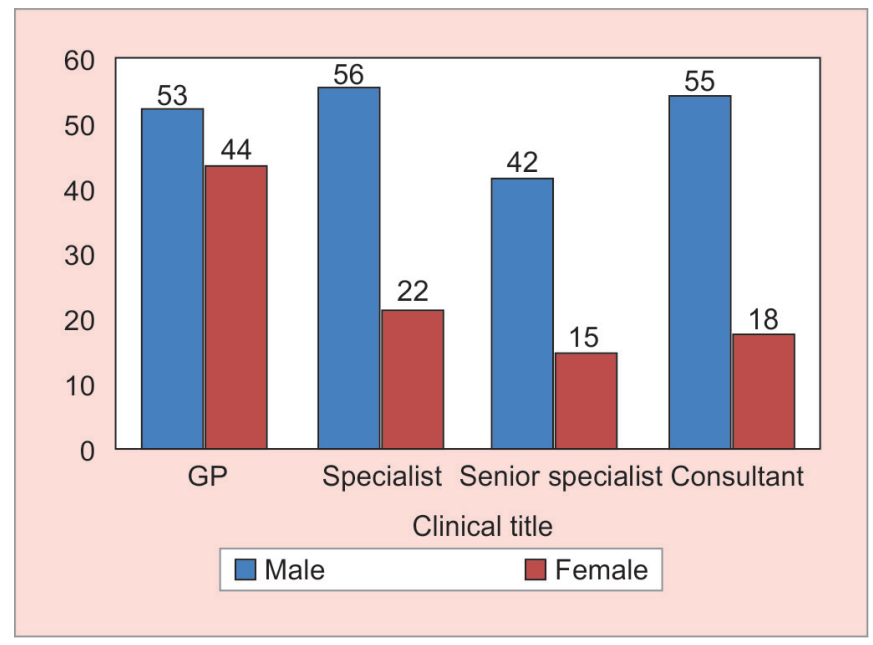

Graph 1: Description of the population according to clinical title the response to the question was compared between Saudi and Non-Saudi dentists, we found the difference to highly significant (Chi-square 8.830, $p<0.004$ ), with Saudi dentists placing more emphasis on the role of the dentist in persuading and encouraging the patient to undergo cosmetic treatment.

When the dentists were asked about the role that a patient's finances played in influencing esthetic dental treatment we found that overall a majority of the dentists felt that it was around $70 \%$ (Chi-square 21.605, $p<0.001$ ). Here too we found no significant difference between clinical titles (Chi-square 4.255, $p$ 0.235) or gender (Chi-square $0.990, p<0.320$ ) in their perception of how the patients' ability to pay for treatment influenced their provision of esthetic dental care. When the dentists were compared according to years of experience we found that the importance placed on the patients' ability to pay for treatment decreased as the number of years of practice increased although the difference was not statistically significant (Chi-square 3.396, $p<0.183$ ). There was no statistical difference between Saudi and non-Saudi dentists in their perception of what influence the patients' ability to pay had on esthetic treatment (Chi-square 2.647, $p<0.107$ ).

When asked about the amount of tooth structure to be reduced for a veneer, we found that a significant majority of the dentists stated that they would reduce less than $2 \mathrm{~mm}$ of tooth structure (Chi-square 139.96, $p<0.0001$ ). When the amount of tooth reduction was quantified and compared using the Kurskul-Wallis test; it was found that the general practitioners were most likely to reduce more than $2 \mathrm{~mm}$ whereas the senior specialists and consultants were likely to be the most conservative in their preparation. However, this difference was not statistically significant. No significant difference was observed when the amount of tooth reduction was compared across the years of experience (Chi-square 2.079, $p<0.354)$, gender (Chi-square $0.088, p<0.766$ ) or nationality (Chi-square 0.039 , $p<0.843)$.

When asked about the obligation of the dentist to the TMJ and occlusions during aesthetic procedures we found that a significant majority of those surveyed felt that the dentist had a full obligation to TMJ and occlusion while performing an esthetic procedure (Chisquare $160.849, p<0.0001)$. When the mean rank of the importance given to TMJ and occlusion was calculated using the Kurskul-Wallis test and compared across groups we found that the importance given to the TMJ and occlusion during esthetic procedures increased with the years of experience. Similarly, consultants and senior specialists were more likely to give full importance to the TMJ and occlusion than a general practitioner. However, these differences were not significant. Furthermore, gender (Chi-square $0.669, p<0.413$ ) and nationality (Chi-square $0.018, p<0.894$ ) played no role in the dentists' perception of their role in considering occlusion and the TMJ during esthetic restorative procedures.

Dentists were asked about their sources of information regarding esthetic dentistry and the differences tested for significance using the Freidman test (Graph 2), a significant majority answered journal articles (Chi-square 146.3, $p<0.0001$ ). The Kruskal-Wallis test showed that choices were not statistically different when compared across the clinical title, gender, years of experience or nationality.

When asked about how they would minimize failures, a majority responded that they would make patients aware of failure or try new materials and techniques. Here too no significant differences were found when responses were compared across the clinical title, gender, years of experience or nationality (Graph 3).

Almost all the dentists surveyed stated that they would promote their practices through a media source, with only 7 (2.2\%) dentists 


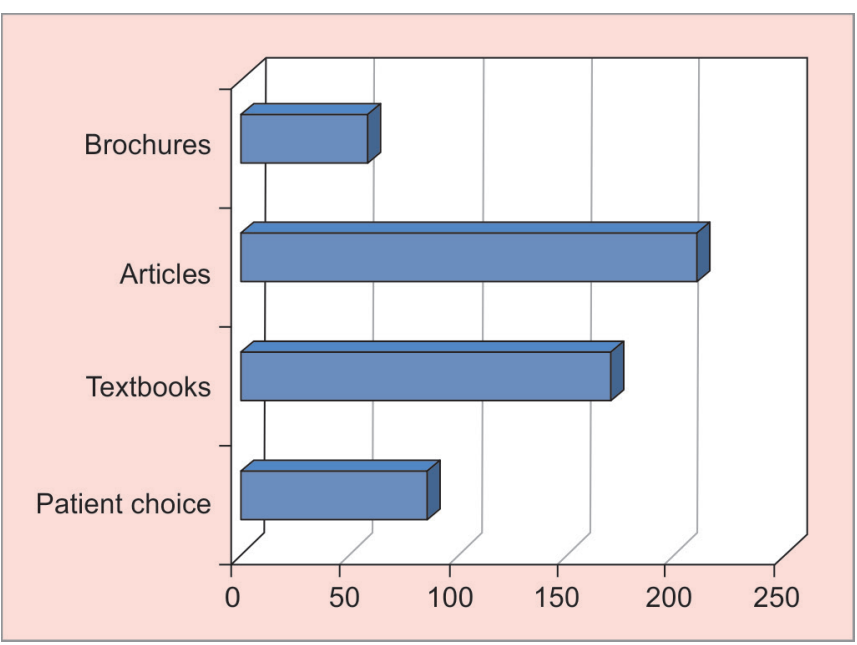

Graph 2: Dentist's perception on the best way to minimize failures

stating that they would not promote or advertise their practice. When asked how they would promote their practice a majority of the dentists (67.3\%) selected multiple options. Pamphlets and brochures, as well as websites, were the most popular choices. Dentists with 1 to 5 years of practice were significantly less likely to choose newspapers as a source to promote their practice. Apart from this, there were no significant differences between gender, clinical title or nationality (Graph 4).

\section{Discussion}

Being a physician means more than just satisfying the patient's demands, ${ }^{9}$ however the distinction between what is good for the patient and what the patient desires is perhaps a fine one in a field like esthetic dentistry. Patient demand for esthetics has increased globally; however, important ethical issues encompass treatment for purely esthetic reasons. ${ }^{22}$ The main goal of our study was to study the attitude of dentists in Saudi Arabia towards ethical considerations that arise from the ever-increasing patient demand for esthetic dentistry.

Our sample comprised of significantly more number of male than female dentists; this, however, is reflective of the demographic distribution of dentists in the Kingdom.

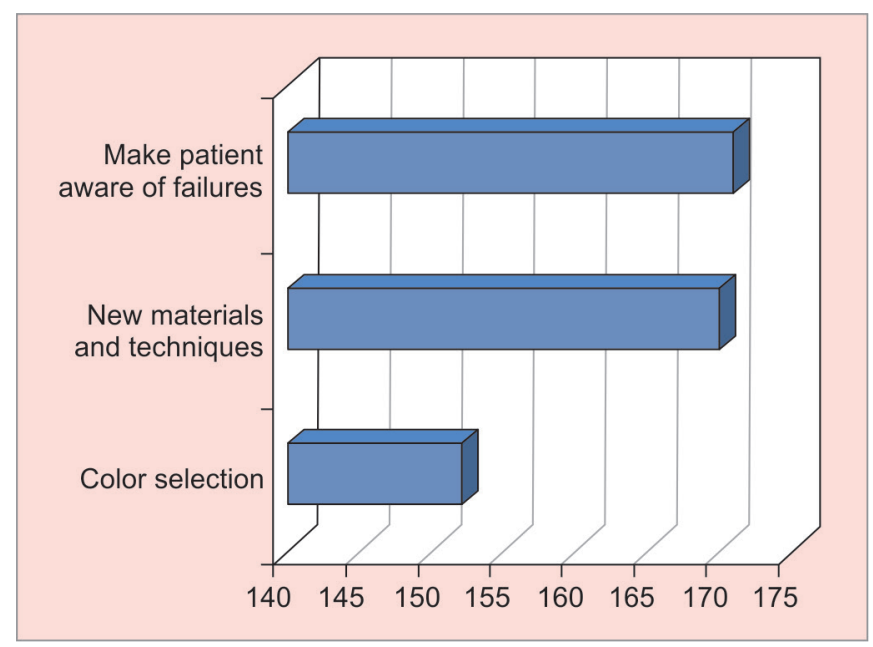

Graph 3: Dentist's perception on the best way to minimize failures
Very often, the perception of esthetics varies between dentists and their patients. ${ }^{23-25}$ In such a scenario the role of the dentist in convincing the patient of the need for esthetic dentistry becomes a question of ethical importance. It was interesting to note that Saudi dentists placed a significantly higher emphasis on the motivation of the patient for esthetic dental treatment.

Patients' finance has always been a much-debated topic in papers on dental ethics. ${ }^{26}$ The question of how to deal with the patient who has not enough funding to cover esthetic dental care is also one that has been debated. ${ }^{26}$ Esthetic procedures are usually not covered by Insurance providers; therefore it was not surprising that a vast majority of the dentists we surveyed, regardless of their gender, clinical title or nationality felt that the patients' finances were an important factor in influencing their decision to render esthetic dental care.

Most of the dentists surveyed seemed to believe in the concept of minimal preparation for veneers. The fact that consultants and senior specialists were less inclined to remove tooth structure for veneers seems to suggest that they are better versed with newer techniques for esthetic dental treatment such as Lumineers ${ }^{\mathrm{TM}}$ which require little or no preparation. ${ }^{27,28}$

Dentists' sources of information have been noted to influence their practice decisions. ${ }^{23,24}$ Our finding that a majority of our dentists got their information from textbooks and journal articles is similar to the findings of Straub-Morarend et al. in the United States. ${ }^{21}$ However, unlike them we did not find a significant difference between years of practice or clinical title. One of the reasons for this could be that our study included dentists who were teaching in universities thus making them more likely to read and have access to journals and textbooks.

The possibility of failure of an esthetic restoration is worrisome to both the dentist and the patient. ${ }^{29}$ Our dentists felt that making the patient aware of the chance of failure and the use of the latest materials was the best way to deal with the possibility of failure. This is similar/dissimilar to the attitudes of dentists in Europe and the US. ${ }^{30}$

The ethical issues involving advertising or promoting a dental practice has been addressed in the literature. ${ }^{31}$ While advertising or promoting dental practice is not unusual and certainly not new $^{32}$ (Grumsen); the impact such advertising has on the people's perception of the dentists' credibility has also to be considered ${ }^{4,33}$ (Christiansen). It is not surprising that in the era of affordable websites, a vast majority of the dentists wished to promote their practice via the internet. The role of the newspapers and print media

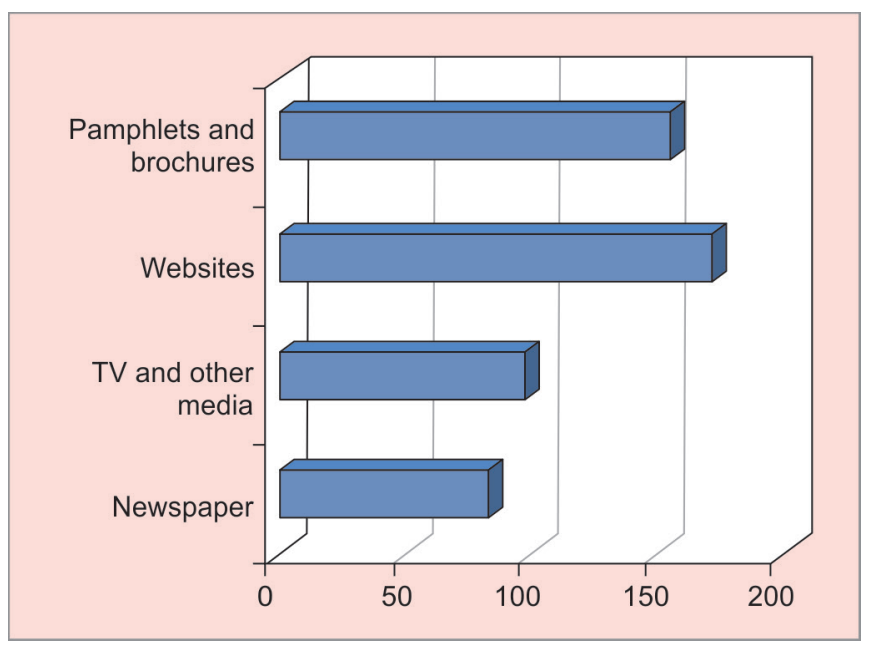

Graph 4: Dentist's sources of promoting their practice 
in promoting dental practice seemed to be reducing as the dentists with 1 to 5 years of experience were significantly less likely to use them to promote their practices.

\section{Conclusion}

Dentists in Saudi Arabia seem to be aware of the ethical implications of practicing esthetic dentistry. While the basic ethical principles do not vary according to the gender, nationality, clinical title or years of practice of the dentist, certain clinical decisions seem to be influenced by them.

\section{References}

1. Bhetala A. Abstract of" Ethics in Dentistry: Changing Trends and Future Challenges". Journal of Long-Term Effects of Medical Implants 2008;18(1).

2. Nash DA. Ethics in dentistry: review and critique of Principles of Ethics and Code of Professional Conduct. Journal of the American Dental Association (1939) 1984 Oct;109(4):597-603.

3. Nash DA. Professional ethics and esthetic dentistry. The Journal of the American Dental Association 1988 Sep 1;117(4):7E-9E.

4. Christensen GJ. The perception of professionalism in dentistry: further reflections on a lively topic. The Journal of the American Dental Association 2002 Apr 1;133(4):499-501.

5. Hofmann BM, Eriksen HM. The concept of disease: ethical challenges and relevance to dentistry and dental education. European Journal of Dental Education: Leading Article 2001 Feb;5(1):2-8.

6. Liebler M, Devigus A, Randall RC, et al. Ethics of esthetic dentistry. Quintessence international 2004 Jun 1;35(6).

7. Newbrun E. Professional ethics and professional etiquette in dentistry: are they compatible? J Hist Dent 2007 Winter;55(3):119-125; discussion 171-185. PubMed

8. Gelbier S, Wright D, Bishop M. Ethics and dentistry: I. The meaning of ethics. Dent Update 2001 Nov;28(9):468-473.

9. Maio G. Being a physician means more than satisfying patient demands: an ethical review of esthetic treatment in dentistry. Eur J Esthet Dent 2007

10. Christensen GJ. The credibility of dentists. J Am Dent Assoc. 2001 Aug;132(8):1163-1165.

11. Wathen WF. The ethics of esthetic dentistty: a neglected topic. Tex Dent J 2006 Oct;123(10):924-925.

12. Kois J "Ethics in Cosmetic Dentistry" AACD, dentaleconomics.com, Jun 1, 2008

13. Goldstein RE. "Guest Editorial: Dentistry - A Health Service?" J Dent res $199372 ; 641$.

14. Stevenson RB. Ethical advertising in dentistry. J Am Coll Dent. 2009.

15. Grumsen S. The era of whiter teeth: advertising in American dentistry 1910-1950. J Hist Dent 2009 Summer-Fall; 57(2):75-84.
16. Hofmann BM, Eriksen HM. The concept of disease: ethical challenges and relevance to dentistry and dental education. European Journal of Dental Education: Leading Article 2001 Feb;5(1):2-8.

17. Jessri M, Fatemi TS. Implication of ethical principles in chair-side dentistry. Iran J Allergy Asthma Immunol Feb 2007; 6(Suppl. 5): 53-59.

18. Padela Al, Shanawani $\mathrm{H}$, Greenlaw J, et al.. The perceived role of Islam in immigrant Muslim medical practice within the USA: an exploratory qualitative study. Journal of Medical Ethics 2008 May 1;34(5): 365-369.

19. Simonsen RJ. Commerce versus care: troubling trends in the ethics of esthetic dentistry. Dent Clin North Am 2007 Apr;51(2):281-287.

20. Wiebe RJ. The New Business Ethics. J Can Dent Assoc 2000;66:248-249.

21. Yeager AL. Dental ethics for the 21st century: learning from the Charter on Medical Professionalism. J Am Coll Dent 2002 Summer;69(3): 53-60. Review.

22. Liebler M, Devigus A, Randall RC, et al.. Ethics of esthetic dentistry. Quintessence international 2004 Jun 1;35(6).

23. Mehl CJ, Harder S, Kern M, et al. Patients' and dentists' perception ofdental appearance. Clin Oral Investig 2011 Apr;15(2):193-199. Epub 2010 Mar 16.

24. Foulger TE, Tredwin CJ, Gill DS, et al. The influence of varying maxillary incisal edge embrasure space and interproximal contact area dimensions on perceived smile aesthetics. Br Dent J 2010 Aug $14 ; 209(3)$

25. Burke FJ. Dentist wealthy, patient healthy? Dent Update 2010 Jun;37(5):277.

26. Ozar DT. Formal instruction in dental professional ethics. J Dent Educ 1985;49:696-701.

27. Veneziani M. Ceramic laminate veneers: clinical procedures with a multidisciplinary approach. The international journal of esthetic dentistry 2017 Dec 1;12(4):426-448.

28. Vanlıoğlu BA, Kulak-Özkan Y. Minimally invasive veneers: current state of the art. Clinical, cosmetic and investigational dentistry 2014; 6:101.

29. Holt VP. The 'daughter test' in aesthetic ('esthetic') or cosmetic dentistry. Dent Update. 2010 Jun;37(5):337-338.

30. Straub-Morarend CL, Marshall TA, Holmes DC, et al. Informational resources utilized in clinical decision making: common practices in dentistry. J Dent Educ. 2011 Apr;75(4):441-452.

31. Haj-Ali RN, Walker MP, Petrie CS, et al. Utilization of evidence-based informational resources for clinical decisions related to posterior composite restorations. J Dent Educ 2005 Nov;69(11):1251-1256.

32. Goldstein RE. Attitudes and problems faced by both patients and dentists in esthetic dentistry today: an AAED membership survey. J Esthet Restor Dent 2007;19(3):164-170.

33. Gaeed SA, Ali AA. Failures of Porcelain Laminate Veneers Using Different Techniques of Bonding, A Comparative Study. Journal of Oral and Dental Research 2017;4(1):35-46. 